\title{
A Robust Hybrid Control for Voltage-Fed Induction Motor Drives based on The Artificial Intelligence Techniques
}

\author{
Amel Ramdane, Amar Betta, Farid Naceri and Sebti Belkacem \\ Department of Electrical Engineering, Faculty of Technology, \\ Batna University, Algeria \\ amel_hse@yahoo.fr
}

\begin{abstract}
In this paper, we introduced a robust approach to induction motor control combining fuzzy logic and variable structure with a sliding mode control. Fuzzy tuning schemes are employed to improve control performance as well as to reduce chattering in the sliding mode. This combination ensures system high performance and fast dynamic response with no overshoot. Becoming a very robust, insensitive to process parameters variation and external disturbances.
\end{abstract}

Keywords: Induction Motor (IM), Sliding Mode Control (SMC), Fuzzy Logic Control (FLC), Fuzzy Logic Sliding Mode Control (FLSMC)

\section{Introduction}

Induction motor (IM) is widely used in various industries as prime workhorses to produce rotational motions and forces as it has many advantages, in terms of low cost, high efficiency, good self starting, simplicity of design, the absence of the collector brooms system and a small inertia. However, induction motor has disadvantages, such as complex, nonlinear and multivariable of nature, in addition of being inherently unable of providing variable speed operation. Generally, variable speed drives for induction motors require both wide operating range of speed and fast torque response, regardless of load variations.

Field oriented control method is used for advanced control of induction motor drives. By providing decoupling of torque and flux control demands, the vector control can govern an induction motor drive similar to a separate excited direct current motor without sacrificing the quality of the dynamic performance.

However, the field oriented control of induction motor drives presents two main problems that have been providing quite a bit research interest in the last decade. The first one relies on the uncertainties in the machine models and load torque, and the second one is the precise computation of the motor speed without using speed sensors.

The decoupling characteristics of the vector control are sensitive to machine parameters variations. Moreover, the machine parameters and load characteristics are not exactly known, and may vary during motor operations. Thus, the dynamic characteristics of such systems are very complex and nonlinear. Therefore, many studies have been made on the motor drives in order to preserve the performance under these parameter variations and external load disturbances, such as nonlinear control, optimal control, variable structure system control, adaptive control and neural control [6-9] and [15].

Sliding mode control (SMC), based on the theory of variable structure systems (VSS), has been applied to robust control of nonlinear systems [2]. Sliding mode control performs well in trajectory tracking of some nonlinear systems. It employs a discontinuous control law to drive the state trajectory toward specified sliding surface and maintain its motion along the sliding 
surface in the state space. It is a common opinion that the major drawback of sliding mode control is the so-called chattering phenomenon. Such a phenomenon consists of the oscillation of the control signal, tied to the discontinuous nature of the control strategy, at a frequency and with an amplitude capable of disrupting, damaging or, at least, wearing the controlled physical system (e.g., in mechanical systems with backlash).

Several methods of chattering reduction have been reported. One approach [3-4] places a boundary layer around the switching surface such that the relay control is replaced by a saturation function. Another method [3,5] replaces a max-min-type control by a unit vector function. These approaches, however, provide no guarantee of convergence to the sliding mode and involve a tradeoff between chattering and robustness.

Chattering Reduction be achieved without harming system robustness by combining the attractive features of fuzzy control with SMC [11-13] and [18]. Fuzzy logic, first proposed by Zadeh [14], has proven to be a potent tool for controlling ill-defined or parameter-variant plants. By incorporating heuristics engineering rules, a fuzzy logic controller can cope well with severe uncertainties, although a heavy computational burden may arise with some implementations. Fuzzy schemes with explicit expressions for tuning can avoid this problem [16].

This paper presents a robust control system using sliding mode control that incorporates a fuzzy tuning technique. The proposed controller is applied to induction motor to control the speed and flux. The control law superposes equivalent control and fuzzy control. An equivalent control law is first designed then we introduce a fuzzy logic control (FLC) in this later the sign function is replaced in order to limit the chattering phenomenon originated by finite-frequency switching control and to preserve the main advantages of the original slidingmode approach (robustness, simplicity, and finite-time convergence).

\section{Mathematical Model of Induction Motor}

The induction motor model in the stationary reference frame can be represented by the following nonlinear differential equations:

$$
\begin{aligned}
& V_{s \alpha}=R_{s} I_{s \alpha}+\frac{d \phi_{s \alpha}}{d t} \\
& V_{s \beta}=R_{s} I_{s \beta}+\frac{d \phi_{s \beta}}{d t} \\
& V_{r \alpha}=0=R_{r} I_{r \alpha}+\frac{d \phi_{r \alpha}}{d t}+\omega \phi_{r \beta} \\
& V_{r \beta}=0=R_{r} I_{r \beta}+\frac{d \phi_{r \beta}}{d t}-\omega \phi_{r \alpha}
\end{aligned}
$$

Where the stator and rotor flux linkages are given by:

$$
\begin{aligned}
& \phi_{s \alpha}=L_{s} I_{s \alpha}+M_{s r} I_{r \alpha} \\
& \phi_{s \beta}=L_{s} I_{s \beta}+M_{s r} I_{r \beta} \\
& \phi_{r \alpha}=L_{r} I_{r \alpha}+M_{s r} I_{s \alpha} \\
& \phi_{r \beta}=L_{r} I_{r \beta}+M_{s r} I_{s \beta}
\end{aligned}
$$

The electromechanical torque is:

$$
T_{e}=p \frac{M_{s r}}{L_{r}} \cdot\left[\bar{\phi}_{r} \wedge \overline{\mathbf{I}}_{\mathrm{s}}\right]=p \frac{M_{s r}}{L_{r}} \cdot\left[\phi_{r \alpha} \cdot i_{s \beta}-\phi_{r \beta} \cdot i_{s \alpha}\right]
$$

The mechanical equation is: 


$$
J \cdot \frac{d \Omega}{d t}=T_{e}-T_{L}-f_{r} \cdot \Omega
$$

The state space representation of the induction motor including both electrical (stator currents and the rotor flux linkages components) and mechanical dynamics can be written as:

$$
\dot{X}(t)=F(X, t)+B(X, t) \cdot U(t)
$$

Where:

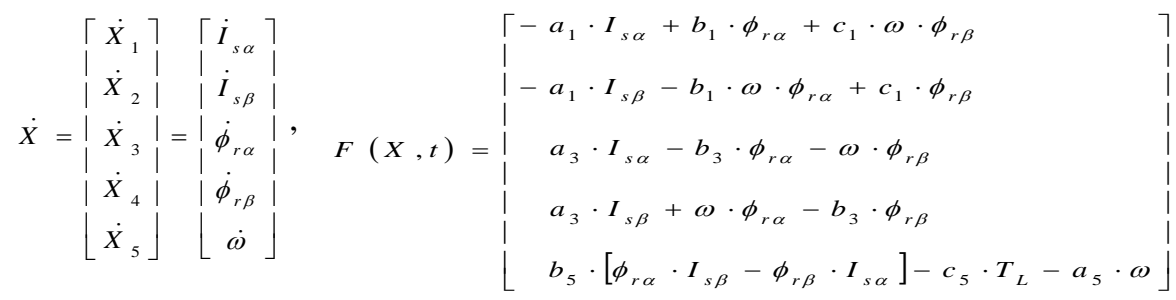

$B(X, t)=\left[\begin{array}{cc}d_{1} & 0 \\ 0 & d_{1} \\ 0 & 0 \\ 0 & 0 \\ 0 & 0\end{array}\right], \quad U(t)=\left[\begin{array}{l}U_{1} \\ U_{2}\end{array}\right]=\left[\begin{array}{l}V_{s \alpha} \\ V_{s \beta}\end{array}\right]$,

$a_{1}=\frac{1}{\sigma \cdot \tau_{s}}+\frac{1-\sigma}{\sigma \cdot \tau_{r}}, \quad b_{1}=\frac{(1-\sigma)}{\sigma \cdot M_{s r} \cdot \tau_{r}}, \quad c_{1}=\frac{(1-\sigma)}{\sigma \cdot M_{s r}}, \quad d_{1}=\frac{1}{\sigma \cdot L_{s}}$,

$a_{3}=\frac{M_{s r}}{\tau_{r}} \quad, \quad b_{3}=\frac{1}{\tau_{r}}$,

$a_{5}=\frac{f_{r}}{p \cdot J} \quad, \quad b_{5}=\frac{p^{2} \cdot M_{s r}}{J \cdot L_{r}} \quad, \quad c_{5}=\frac{p}{J}$

\begin{tabular}{|c|c|c|c|c|c|c|c|}
\hline$s, r$ & $\begin{array}{l}\text { Stator and } \\
\text { rotor index. }\end{array}$ & $I$ & Current, [A]. & $\omega$ & $\begin{array}{l}\text { Rotor angular } \\
\text { frequency, }[\mathrm{rad} / \mathrm{s}] \text {. }\end{array}$ & $\sigma$ & $\begin{array}{l}\text { Total leakage } \\
\text { coefficient. }\end{array}$ \\
\hline$r e f$ & $\begin{array}{l}\text { Reference } \\
\text { value. }\end{array}$ & $\mathbf{\Omega}$ & $\begin{array}{l}\text { Mechanical speed, } \\
{[\mathrm{rad} / \mathrm{s}] .}\end{array}$ & $f_{r}$ & $\begin{array}{l}\text { Viscose friction } \\
\text { coefficient, } \\
\text { [N.m.s/rad]. }\end{array}$ & $\begin{array}{l}\boldsymbol{R}_{s} \\
\boldsymbol{R}_{r}\end{array}$ & $\begin{array}{l}\text { Stator, rotor } \\
\text { resistance, }[\Omega] .\end{array}$ \\
\hline$\alpha, \beta$ & $\begin{array}{l}\text { Rotor } \\
\text { reference } \\
\text { frame. }\end{array}$ & $\phi$ & Flux, [Wb]. & $J$ & $\begin{array}{l}\text { Moment of inertia, } \\
{\left[\mathrm{Kg} \cdot \mathrm{m}^{2}\right] .}\end{array}$ & $\begin{array}{l}L_{s} \\
L_{r} \\
M_{s r}\end{array}$ & $\begin{array}{l}\text { Stator, rotor and } \\
\text { mutual inductance, } \\
{[\mathrm{H}] .}\end{array}$ \\
\hline $\boldsymbol{V}$ & Voltage, [V]. & $T_{e}$ & $\begin{array}{l}\text { Electromechanical } \\
\text { torque, [N.m]. }\end{array}$ & $p$ & Pole pair number. & $\begin{array}{c}\tau_{s}, \\
\tau_{r}\end{array}$ & $\begin{array}{l}\text { Stator and Rotor time } \\
\text { constant, [s]. }\end{array}$ \\
\hline
\end{tabular}

With: $\tau_{s}=\frac{L_{s}}{R_{s}}, \tau_{r}=\frac{L_{r}}{R_{r}} \quad$ and $\quad \sigma=1-\frac{M_{s r}^{2}}{L_{s} L_{r}}$.

\section{Nomenclature}




\section{Design of the Control Manifold}

The design procedure for a state based sliding mode controller can be divided into two stages [1]:

Step 1: Finding the switching function $S(X)$ defined as:

$$
S(X)=\left(\frac{\partial}{\partial t}+\lambda\right)^{r-1} \cdot e(X)
$$

Such that the internal dynamics in sliding mode is stable.

$s(x)$ is the sliding surface or switching surface. It is a surface in $\Re^{n}$ that divides the state space into two disjoint parts: $S(x)>0$ and $S(x)<0$.

Step 2: Designing a controller $U$, which insures that the sliding mode is reached and subsequently maintained [1].

$$
U=\left\{\begin{array}{lll}
U^{e q}+U^{n} & \text { if } \quad S(X)>0 \\
U^{e q}-U^{n} & \text { if } \quad S(X)<0
\end{array}\right.
$$

When the system is in sliding mode, the trajectory will remain on the switching surface. This can be expressed by:

$$
S(X)=0 \text { and } \dot{S}(X)=0
$$

This condition is called invariance condition of the sliding surface.

The total control is :

$$
U=U^{e q}+U^{n}
$$

Where:

$$
\begin{aligned}
& U^{e q}: \text { The equivalent control. } \\
& U^{n}: \text { The attractive control. }
\end{aligned}
$$

The derivative of the surface $s(x)$ is:

$$
\dot{S}(X)=\frac{\partial S}{\partial t}=\frac{\partial S}{\partial X} \cdot \frac{\partial X}{\partial t}=\frac{\partial S}{\partial X} \cdot \dot{X}
$$

By introducing (5) and (9) in (10), we obtain:

$$
\dot{S}(X)=\frac{\partial S}{\partial X} \cdot\left[F(X, t)+B(X, t) \cdot U^{e q}\right]+\frac{\partial S}{\partial X} \cdot\left[B(X, t) \cdot U^{n}\right]
$$

During the sliding mode and the permanent state, the surface is zero $(S(X)=0)$ and therefore, its derivative and the discontinuous part are also zero $\left(\dot{s}(X)=0\right.$ and $\left.U^{n}=0\right)$. Hence, we deduce the expression of the equivalent control:

$$
\frac{\partial S}{\partial X} \cdot\left[F(X, t)+B(X, t) \cdot U^{e q}\right]=0
$$




$$
U^{e q}=-\left[\frac{\partial S}{\partial X} \cdot B(X, t)\right]^{-1} \cdot\left[\frac{\partial S}{\partial X} \cdot F(X, t)\right]
$$

For the equivalent command can take a finite value, it must:

$$
\frac{\partial S}{\partial X} \cdot B(X, t) \neq 0
$$

By replacing the equivalent control by expression in (14) yields the new expression for the derivative of the surface:

$$
\begin{gathered}
\dot{S}(X)=\frac{\partial S}{\partial X} \cdot\left[B(X, t) \cdot U^{n}\right] \\
S(X) \cdot \dot{S}(X)=S(X) \frac{\partial S}{\partial X} \cdot\left[B(X, t) \cdot U^{n}\right]<0
\end{gathered}
$$

The basic form of the attractive control $U^{n}$ is a relay. In this case the discontinuous control is given by [1]:

$$
U^{n}=-k \cdot \operatorname{sign}(S(X))
$$

Where $k$ is a strictly positive constant.

\section{Design of Fuzzy Logic Sliding Mode FLSMC}

The controllers of speed and rotor flux are substituted by a fuzzy logic sliding mode control.

$$
U_{F L S M C}=U^{e q}+U^{F u z z y}
$$

Where:

$$
U^{\text {Fuzzy }} \text { : FLC replacing the attractive control. }
$$

\subsection{Synthesis of Sliding Mode Controllers SMC}

The first step of sliding mode control design is to select a sliding surface that models the desired closed-loop performance in state variable space. Then design the control such that the system state trajectories are forced toward the sliding surface and stay on it. Now, suppose that a sliding surface is given as:

$$
\begin{gathered}
S_{1}\left(e_{1}\right)=\lambda_{1} \cdot e_{1}+\dot{e}_{1} \quad \text { with: } e_{1}=\omega_{r e f}-\omega \\
S_{2}\left(e_{2}\right)=\lambda_{2} \cdot e_{2}+\dot{e}_{2} \quad \text { with: } e_{2}=\phi_{r r e f}^{2}-\phi_{r}^{2}
\end{gathered}
$$

Where $\lambda_{1}$ and $\lambda_{2}$ are non-zero positive gains.

Our objective is to control rotor speed $\omega$ and rotor magnitude flux given by: $\phi_{r}^{2}=\phi_{r \alpha}^{2}+\phi_{r \beta}^{2}$ Here $\phi_{\text {ref }}$ and $\omega_{\text {ref }}$ are the desired flux and speed respectively.

$$
S_{1}\left(e_{1}\right)=\lambda_{1} \cdot\left(\omega_{r e f}-\omega\right)+\left(\dot{\omega}_{r e f}-\dot{\omega}\right)
$$




$$
S_{2}\left(e_{2}\right)=\lambda_{2} \cdot\left(\phi_{\text {rref }}^{2}-\phi_{r}^{2}\right)+\left(\dot{\phi}_{\text {rref }}^{2}-\dot{\phi}_{r}^{2}\right)
$$

The development of calculated derivatives of the surfaces gives:

$$
\begin{aligned}
\dot{S}_{1}\left(e_{1}\right)= & \lambda_{1}\left(\dot{\omega}_{r e f}-\dot{\omega}\right)+\left(\ddot{\omega}_{r e f}-\ddot{\omega}\right) \\
= & \lambda_{1} \cdot \dot{\omega}_{r e f}+\ddot{\omega}_{r e f}-\left(\lambda_{1}-a_{5}\right) \cdot \dot{X}_{5} \\
& +b_{5}\left[a_{1}\left(X_{2} \cdot X_{3}-X_{1} \cdot X_{4}\right)+c_{1} \cdot \phi_{r}^{2} \cdot X_{5}+X_{1} \cdot X_{4}-X_{2} \cdot X_{3}\right]+ \\
& +c_{5} \cdot \dot{T}_{L}+b_{5} \cdot d_{1} \cdot X_{4} \cdot U_{1}-b_{5} \cdot d_{1} \cdot X_{3} \cdot U_{2} \\
\dot{S}_{2}\left(e_{2}\right)= & \lambda_{2}\left(\dot{\phi}_{r r e f}^{2}-\dot{\phi}_{r}^{2}\right)+\left(\ddot{\phi}_{r r e f}^{2}-\ddot{\phi}_{r}^{2}\right) \\
= & \lambda_{2} \cdot \dot{\phi}_{r r e f}^{2}+\ddot{\phi}_{r r e f}^{2}-\left(\lambda_{2}-2 \cdot b_{3}\right) \cdot \dot{\phi}_{r}^{2} \\
& -2 \cdot a_{3}\left[X_{1} \cdot \dot{X}_{3}+X_{2} \cdot \dot{X}_{4}-a_{1}\left(X_{1} \cdot X_{3}+X_{2} \cdot X_{4}\right)+b_{1} \cdot I_{s}^{2}\right] \\
& -2 \cdot a_{3} \cdot d_{1} \cdot X_{3} \cdot U_{1}-2 \cdot a_{3} \cdot d_{1} \cdot X_{4} \cdot U_{2}
\end{aligned}
$$

With:

$$
I_{s}^{2}=I_{s \alpha}^{2}+I_{s \beta}^{2}
$$

The surfaces derivatives can be rearranged in the following condensed form:

$$
\begin{aligned}
& \dot{S}=\left[\begin{array}{ll}
\dot{S}_{1}\left(e_{1}\right) & \dot{S}_{2}\left(e_{2}\right)
\end{array}\right]^{T}=G(X)+Q(X) \cdot U \\
& G(X)=\left[G_{1}(X) \quad G_{2}(X)\right]^{T} \\
& G_{1}(X)=\lambda_{1} \cdot \dot{\omega}_{r e f}+\ddot{\omega}_{r e f}-\left(\lambda_{1}-a_{5}\right) \cdot \dot{X}_{5}+ \\
& +b_{5}\left[a_{1}\left(X_{2} \cdot X_{3}-X_{1} \cdot X_{4}\right)+c_{1} \cdot \phi_{r}^{2} \cdot X_{5}+X_{1} \cdot X_{4}-X_{2} \cdot X_{3}\right] \\
& +c_{5} \cdot \dot{T}_{L} \\
& G_{2}(X)=\lambda_{2} \cdot \dot{\phi}_{\text {ref }}^{2}+\ddot{\phi}_{\text {ref }}^{2}-\left(\lambda_{2}-2 \cdot b_{3}\right) \cdot \dot{\phi}_{r}^{2}- \\
& -2 \cdot a_{3}\left[X_{1} \cdot \dot{X}_{3}+X_{2} \cdot \dot{X}_{4}-a_{1}\left(X_{1} \cdot X_{3}+X_{2} \cdot X_{4}\right)+b_{1} \cdot I_{s}^{2}\right] \\
& Q(X)=\left[\begin{array}{ll}
b_{5} \cdot d_{1} \cdot X_{4} & -b_{5} \cdot d_{1} \cdot X_{3} \\
-2 \cdot a_{3} \cdot d_{1} \cdot X_{3} & -2 \cdot a_{3} \cdot d_{1} \cdot X_{4}
\end{array}\right]
\end{aligned}
$$

The necessary condition for the system states to follow the trajectory defined by the sliding surfaces is: $S_{i}\left(e_{i}\right)=0,(i=1,2)$, the equivalent part $U^{e q}$ is the control provided that $\dot{S}_{i}\left(e_{i}\right)=0$.

So for the nominal system $\dot{S}_{i}\left(e_{i}\right)=0$, we have:

$$
\begin{aligned}
\dot{S}=0 & \Rightarrow\left[\begin{array}{ll}
\dot{S}_{1}\left(e_{1}\right) & \dot{S}_{2}\left(e_{2}\right)
\end{array}\right]^{T}=0 \\
& \Rightarrow G(X)+Q(X) \cdot U=0 \\
& \Rightarrow \quad U=-Q^{-1}(X) \cdot G(X)=U^{e q}=\left[\begin{array}{ll}
V_{s \alpha} & V_{s \beta}
\end{array}\right]^{T}
\end{aligned}
$$

\subsection{Design of Fuzzy Logic Controllers FLC for Induction Motor Drive}

The proposed fuzzy controller is presented in Figure 1. The FLSMC is introduced to replace the sign function in SMC controller. 


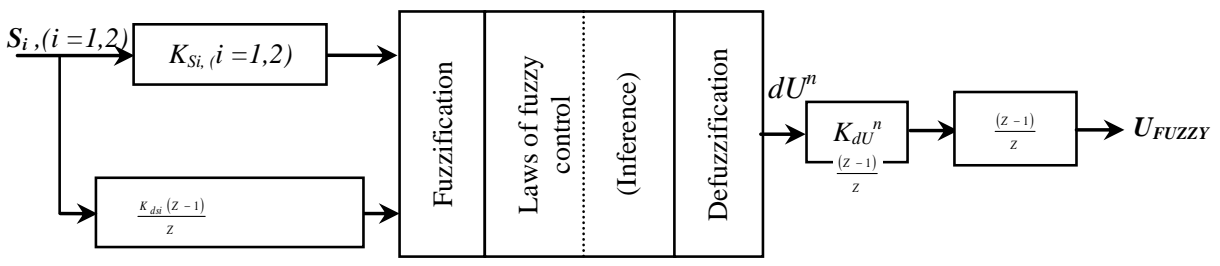

Figure 1. Diagram of the Fuzzy Logic Sliding Mode Controllers

FLSMC in this system uses Mamdani fuzzy inference system to relate two input variables to one output variable. The first input variable is the sliding surface $\left(S_{i}\left(e_{i}\right)=0,(i=1,2)\right)$, while the other input is the change of sliding surface $\left(d S_{i},(i=1,2)\right)$. The output variable is the change of controllers $\left(d U_{i},(i=1,2)\right)$.

The membership functions for input and output variables are shown in Figure 2.

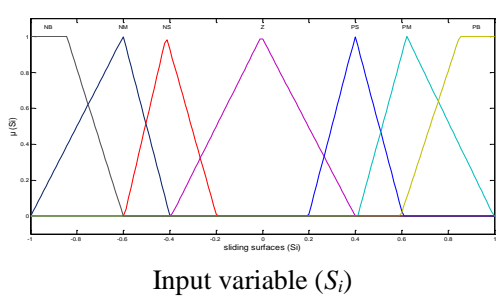

(a)

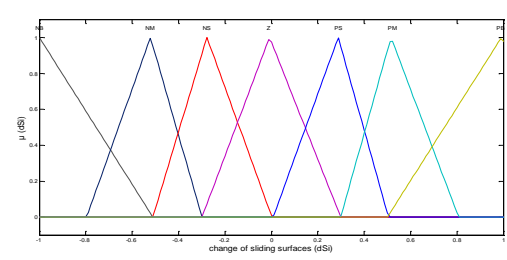

Input variable $\left(d S_{i}\right)$

(b)

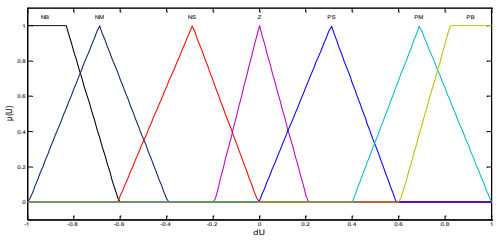

Output variable $\left(d U_{i}\right)$

(c)

Figure 2. (a) Membership function for input variable (Si).

(b) Membership function for input variable (dSi).

(c) Membership function for output variable (dUi).

All input and output variables were normalized to fit the range of $\left(\begin{array}{ll}-1 \text { to } 1 & 1\end{array}\right)$. The output variable $\left(\boldsymbol{d} U_{i}\right)$ is used to calculate the required change of controllers which will be used to control the speed and rotor flux of induction motor. All fuzzy rules used in the proposed system are summarized in Table 1:

Table 1. Inference Table (Rules)

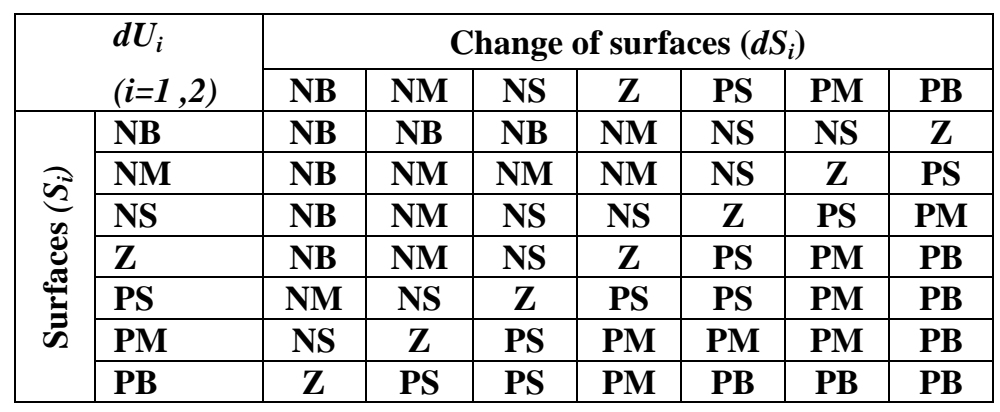


For the defuzzifier of the crisp value of output $\left(\boldsymbol{d} \boldsymbol{U}_{i}\right)$, we use the center of area defuzzifier.

\section{Simulation and Discussion Results}

The behaviour of the overall system is tested by simulation for three phase induction machine represented in Figure 3.

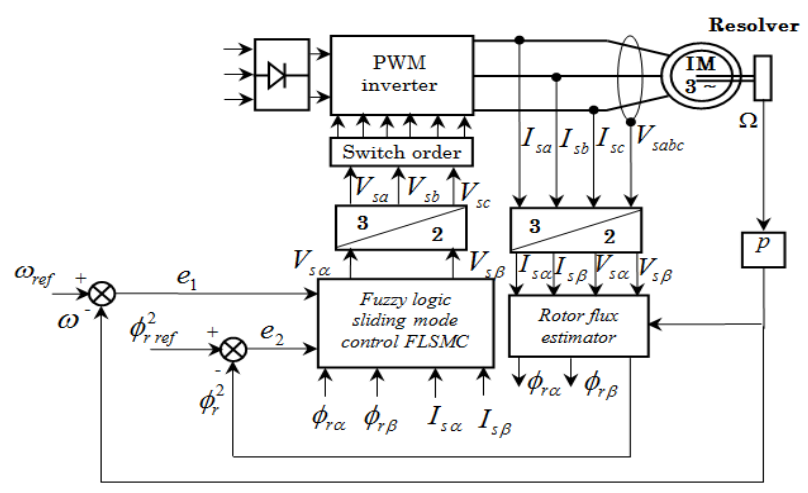

\section{Figure 3. Principe Scheme of the Proposed FLSMC of IM}

A series of simulation tests were carried out on induction motor drive using both the sliding mode controller SMC and fuzzy logic sliding mode controller (FLSMC), for various operating conditions.

Figure 4 shows speed response with both the SMC and FLSMC controller. The FLSMC controller performed with better performance as far as the rise time and steady state error are concerned. The speed response is well damped within a rise time of $0.025 \mathrm{~s}$.

\section{Speed [rd/s)]}

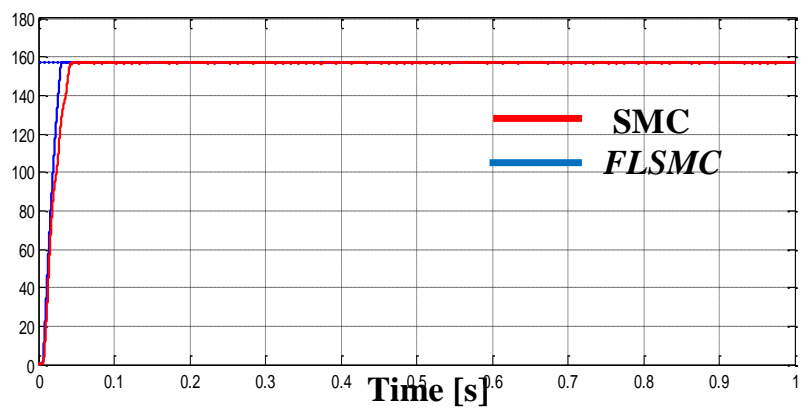

Figure 4. Speed Response Comparison at No Load $\left(T_{L}=0\right)$

In Figure 5, A comparison test using SMC and FLSMC controller has been carried out starting-up towards $1500 \mathrm{rpm}$ at no load $\left(T_{L}=0 \mathrm{~N} . \mathrm{m}\right)$.

In this test, the simulation results show that the FLSMC gives better performances in minimizing of the torque ripple with higher tracking precision. 

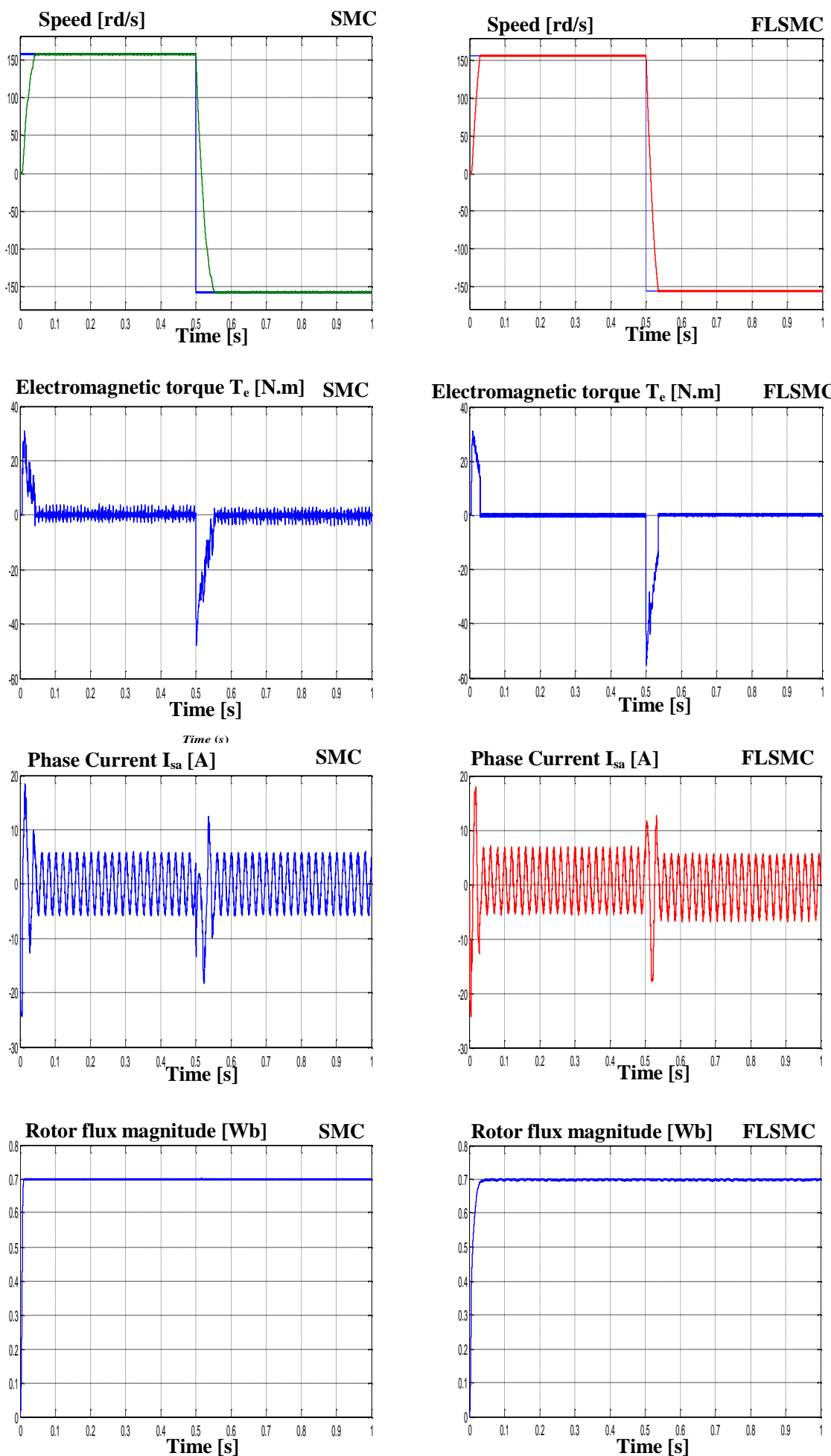

Figure 5. Comparison Results between the SMC and FLSMC at no load $\left(T_{L}=0\right.$ N.m)

The simulation test reported in Figure 6 reveals that the load disturbance rejection capabilities of each controller when using a step load from 0 N.m to 5 N.m at 0.5 seconds. 


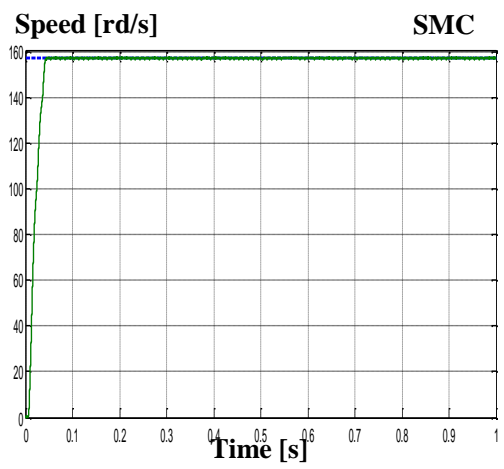

Electromagnetic torque $T_{\mathrm{e}}[\mathbf{N} . \mathrm{m}] \quad$ SMC
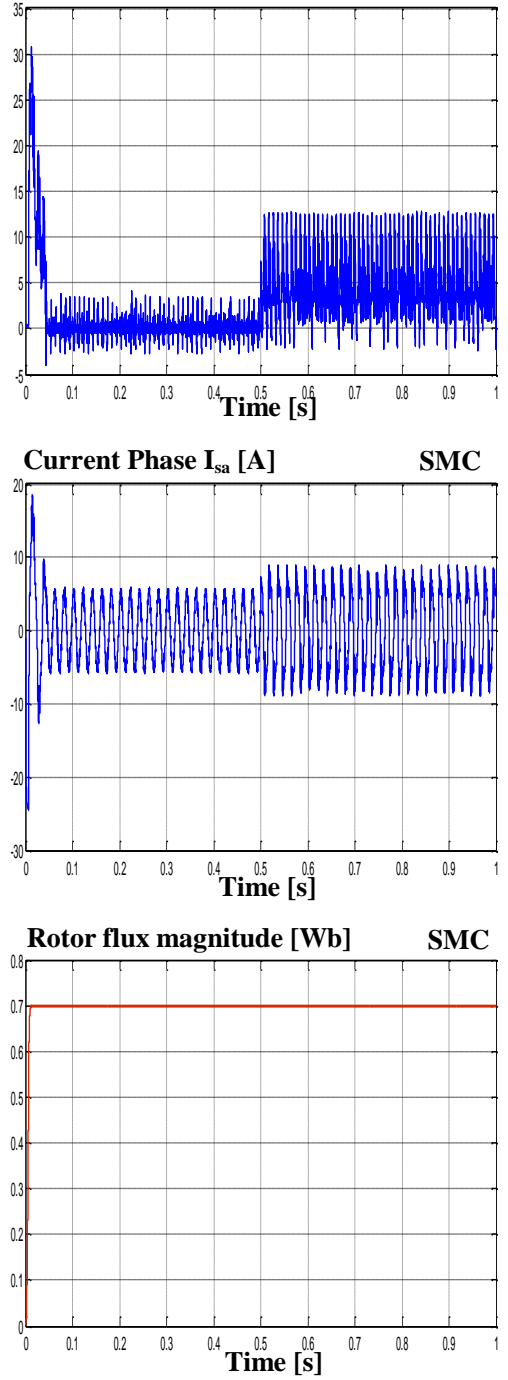

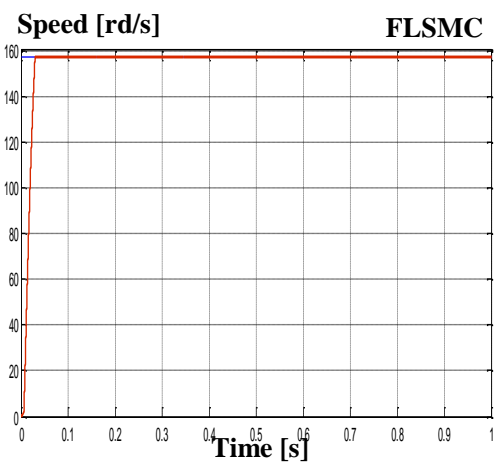

Electromagnetic torque $T_{e}$ [N.m] FLSMC
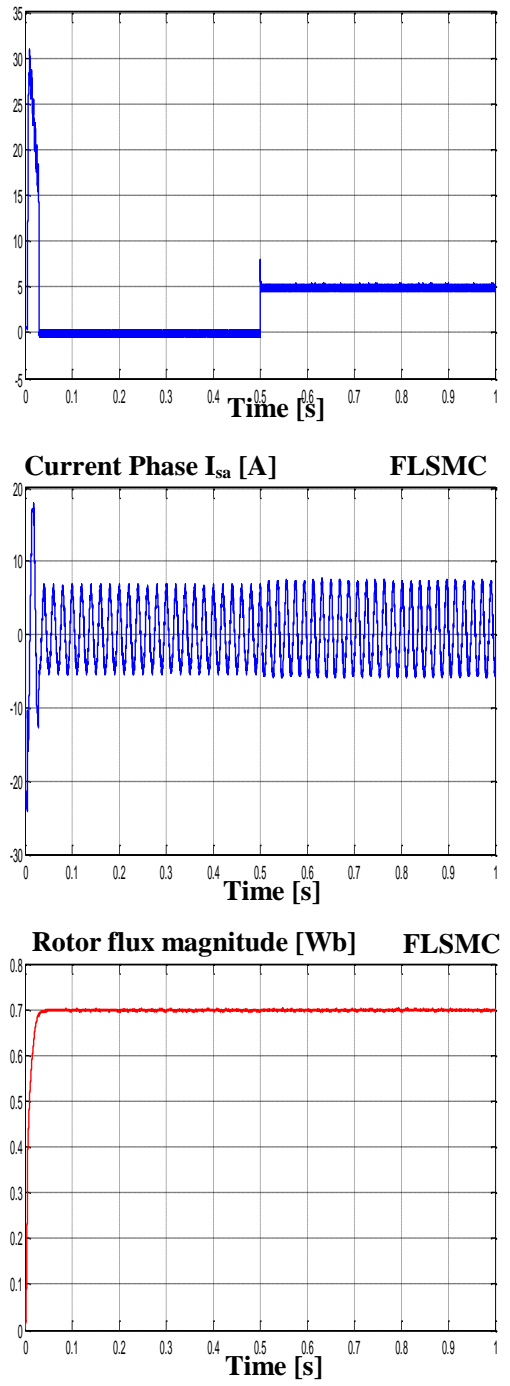

Figure 6. Comparison Results between the SMC and FLSMC when Load $\left(T_{L}=5\right.$ N.m)

A test of robustness has been also held by tuning the rotor resistance parameter with the over-estimation. 
Figure 7 represents the test of robustness realized with the sliding mode controller SMC and FSMC for different value of the rotor resistance.
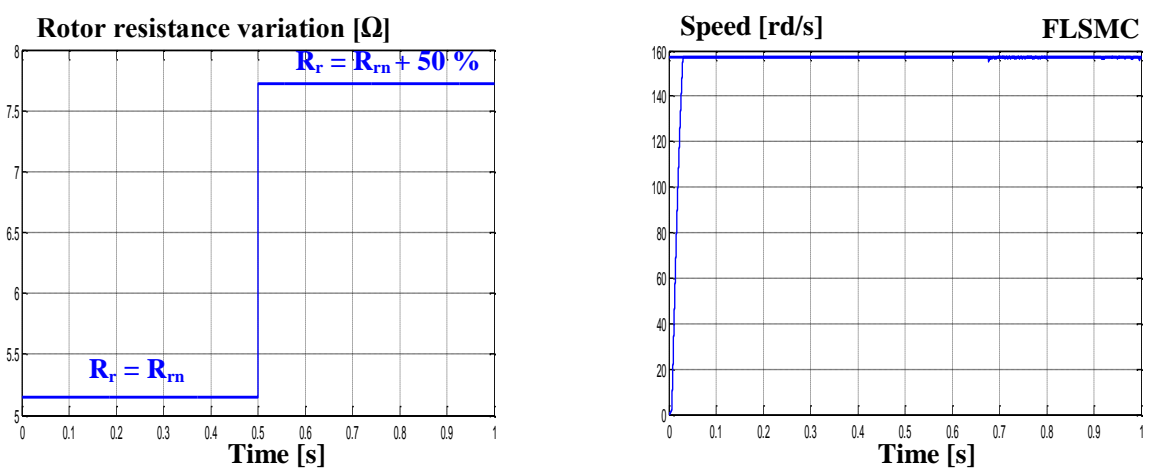

Figure 7. Simulation Results under Rotor Resistance Variation

Figure 8 shows the test of robustness realized with the sliding mode controller SMC and FSMC for different values of the moment of inertia.
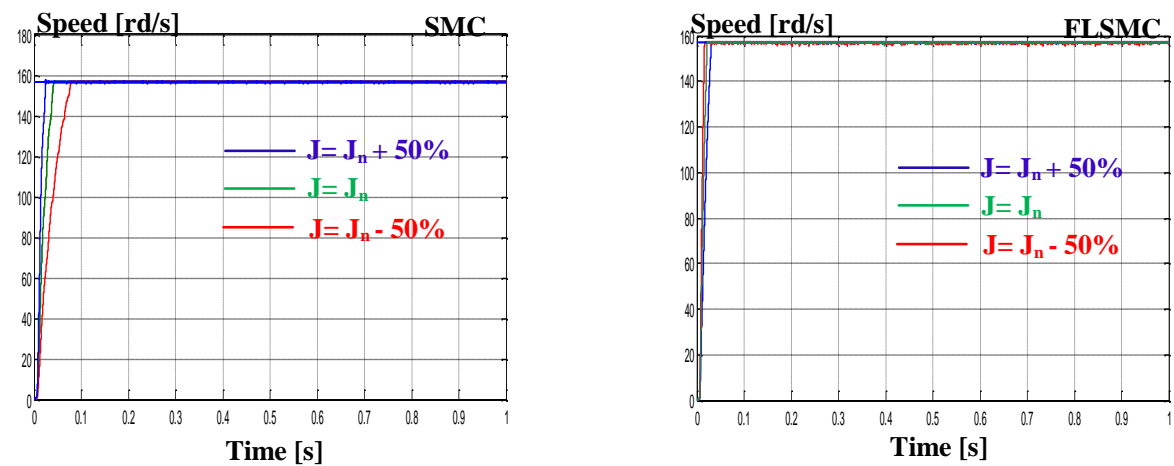

Figure 8. Simulation Results under Variations of the Moment of nertia

To be noted that, the variation of the moment of inertia has no significant influence on performances of the FLSMC proposed control.

\section{Conclusion}

A new hybrid technique control system to indirect vector controlled induction motor combining the features of SMC and fuzzy control has been presented in this paper. Fuzzy tuning schemes are employed to reduce chattering and accelerate reaching the steady state phase. The FLSMC has the advantage in handling the torque ripple phenomenon and reducing the number of the fuzzy rules and these, themselves, were simplified. The drive system has been simulated with fuzzy logic controller and SMC controller and their performance have been compared. Here, simulation results shows that the designed FLSMC controller realizes a better dynamic behavior of the motor with a rapid settling time, no overshoot and has better performance than SMC controller. FLSMC control is more robust with respect to parameter variations and external disturbances. 


\section{References}

[1] L. Fridman, J. Moreno and R. Iriarte, "Sliding modes after the first decade of the 21 st century", LNCIS, vol. 412, Springer-Verlag Berlin Heidelberg (2011).

[2] W.S.Lin and C. S.Chen, " Robust adaptive sliding mode control using fuzzy modeling for a class of uncertain MIMO nonlinear systems”, IEE Proceeding, Control Theory and applications, Vol. 149, no. 3, (2002) May.

[3] Q. P. Ha, Q. H. Nguyen, D. C. Rye and H. F. Durrant-Whyte, "Fuzzy sliding-mode controllers with applications", IEEE transactions on industrial electronics", Vol. 48, no. 1, (2001) February.

[4] J. J. Slotine and S. S. Sastry, "Tracking control of nonlinear systems using sliding surfaces, with application to robot manipulators", International journal of control, vol. 38, (1983), pp. 465-492.

[5] S. K. Spurgeon, "Choice of discontinuous control component for robust sliding mode performance", International journal of control, Vol. 53, (1991), pp.161-179.

[6] S.J. Huang, C.L. Huang and Y.S. Lin, "Sensorless speed identification of vector controlled induction drives via neural network based estimation", Electric power systems research, Vol.48, (1998), pp. 1-10.

[7] F.K. Lin and C.M. Liaw, "Control of indirect field-oriented induction motor drives considering the effects of dead-time and parameter variations", IEEE transactions on industrial electronics, Vol. 40, (1993), pp. 486495.

[8] R.Marino, S. Peresada and P.Tomei, "Adaptive output feedback control of current-fed induction motors with uncertain rotor resistance and load torque", Automatica, Vol.34, (1998), pp. 617-624.

[9] G.S.KIM, I.J. HA and M.S.KO, "Control of induction motors for both high dynamic performance and high power efficiency", IEEE transactions on industrial electronics, Vol. 39, (1992), pp. 323-333.

[10] I. Bendaas, F. Naceri, "A new method to minimize the chattering phenomenon in sliding mode control based on intelligent control for induction motor drives", Serbian journal of electrical engineering, Vol.10, no.2, (2013) June, pp. 231-246.

[11] Y. S. Lu and J. S. Chen, "A self-organizing fuzzy sliding-mode controller design for a class of nonlinear servo systems", IEEE transactions on industrial electronics, vol. 41, (1994) October, pp. 492-502.

[12] S. Y. Wang, C. M. Hong, C. C. Liu, and W. T. Yang, "Design of a static reactive power compensator using fuzzy sliding mode control”, International journal of control, Vol. 63, no. 2, (1996), pp. 393-412.

[13] Q. P. Ha, D. C. Rye and H. F. Durrant-Whyte, "Fuzzy moving sliding mode control with application to robotic manipulators", Automatica, Vol.35, no. 4, (1999), pp. 607-616.

[14] L. A. Zadeh, "Fuzzy sets, Information and Control", Vol. 8, (1965), pp. 338-353.

[15] R. Ortega, C. Canudas and I. S. Seleme, "Nonlinear control of induction motors: torque tracking with unknown load disturbances", IEEE Transactions on Automatic Control, Vol. 38, (1993), pp. 1675-1680.

[16] Q. P. Ha, "Robust sliding mode controller with fuzzy tuning", IEEE Electronics Letters, Vol. 32, no. 17, (1996), pp. $1626-1628$.

[17] L. Barazane, A. Khwaldeh, M. M. S. Krihan and P. Sicard, "Using an adaptive fuzzy-logic system to optimize the performances and the reduction of chattering phenomenon in the control of induction motor", Serbian journal of electrical engineering, Vol. 6, no.2, (2009) November, pp. 267-284.

[18] T. Laamayad, F. Naceri, R. Abdessemed and S. Belkacem, "fuzzy sliding mode strategy for control of the dual star induction machine", Journal of Electrical Engineering, Vol. 13, no. 01, (2013), pp. 216-223.

\section{Author}

Amel Ramdane, She received the M.S degree in Electrical engineering from Batna University, Algeria in 2004. Presently, She is working as an Assistant Professor at Batna University, Algeria. Her research interests are the induction machine, fuzzy control, robust control, adaptive control. 